\title{
Students' Ability Levels and Effectiveness of Problem-Solving Instructional Strategy
}

\author{
Francis A. Adesoji \\ Department of Teacher Education, University of Ibadan, Ibadan, Nigeria \\ E-mail: francisadesoji@yahoo.com
}

KEYWORDS Ability levels; students; senior secondary school; problem-solving strategy; effectiveness

\begin{abstract}
The paper investigated the impact of problem-solving instructional strategy on the performances of students of different ability levels in Chemistry. The performances of students in the high, medium and low ability levels in a problem-solving task were compared after exposing them to teacher-directed problem-solving instruction. It was detected that there was no significant difference $(\mathrm{P}>0.05)$ in the performance of students in the different ability levels after the treatment. Method of instruction was found to influence academic achievement of low achievers as found out by Long (1981) and Kempa and Dupe (1974) and that problem solving in science depends on student's cognitive ability level (Salami, 2000). The need for good instructional strategy like problem-solving technique was advocated for teachers of science. This would go a long way in improving problem-solving skills of students no matter their ability level.
\end{abstract}

\section{INTRODUCTION}

Students are not the same especially when we find out the rate at which facts and principles in sciences are being assimilated. This is to say that, there is disparity in the ability to perform specific tasks. According to Adesoji (1992), all aspects of science could be said to be problem solving and students have varying ability when they are confronted with problems to solve. It is the view of Salami (2000) that problem solving in science depends on student's cognitive ability level. This statement corroborated Niaz's (1996) finding that students who were successful in solving chemical problems and those with high proportional reasoning ability tend to use algorithmic reasoning strategies more frequently than non-successful and low proportional reasoning students.

Several studies within the Nigerian environment have, however, shown that learners are qualitatively different in their ability levels and in learning problems (Usua, 1974, Ehindero, 1980). Some studies have also shown that method of instruction can influence the performances of low achieving students, (Kempa and Dube, 1974; Long, 1981;Adesoji, 1992; Okebukola, 1992; Lavioe, 1993 and Iroegbu, 1998). However, achievements of low ability students have been found to be lowest while that of high ability students was the highest ( Kempa and Dube, 1974; Roberts,1995). It has also been observed that problem-solving strategies were effective in teaching students of different ability levels (Adesoji, 1995, 1997).
The problem-solving instructional technique, either as a teaching strategy by the teacher or as a self-learning technique, has been found to be useful in teaching students (Bello, 1985, Frazer and Sleet, 1984, Inventash, 1968, Mettes, Roosink, Pilot and Kramers pals, 1980, Adesoji, 1992, Agbayewa, 1996). It is therefore necessary to find out whether the teacher-directed problemsolving instructional strategy would have any effect on students' achievement in science, taking into cognizance their different ability levels.

\section{Purpose of the Study}

The purpose of the study is to find out whether the performances of students in a problem-solving task will reflect their ability levels after exposing them to teacher-directed problem-solving strategy.

\section{Hypothesis}

There is no significant difference in the performances of students in the high, medium and low ability groups exposed to teacher-directed problem-solving strategy when they solve problems in selected concepts on electrolysis.

\section{METHODOLOGY}

Population: One hundred and twenty (120) Senior Secondary School class two chemistry students were randomly selected from four 
schools, which were randomly picked in Ife Central, Ife South and Atakumosa Local Government Areas of Osun State, Nigeria. Thirty students were randomly selected from each of the four schools. The participants were stratified into three ability groups of high, medium and low. This was done by making use of the scores of students in previous chemistry examinations conducted by the schools.

Treatment and Instrument: One treatment and an instrument were developed for use for the study. The treatment was Problem-Solving Technique Procedure (PSTP) while the instrument was a multiple test used for both pretest and post-test.

The PSTP was based on electrolysis as contained in the Senior Secondary School chemistry curriculum. It contained (i) prerequisite concepts for electrolysis that is, ionic theory, oxidation-reduction and mole concept, (ii) principles of electrolysis. The instrument was used for pretest and post-test and students were asked to show their procedure in each of the problems.

Validity and Reliability: The content of the PSTP was assessed and corrected by five chemistry education lecturers and it was certified to be adequate for teaching steps and strategies of problem solving.

The twenty-five multiple choice questions were obtained from thirty-five questions initially constructed by the researcher. Ten of the questions were not selected because their levels of difficulties were either too low or too high. The reliability determination was carried out using Kuder-Richardson (KR - 21) formula. KR $-21=0.624$.

Procedure: Teachers of the subjects taught electrolysis and its prerequisite concepts for three weeks after administering the pretest. The researcher taught the problem-solving technique for another three weeks making a total of six weeks. Many questions were solved and students were given enough questions to practice with. They were exposed to post-test after the treatment.

\section{RESULTS}

The pretest scores of the students in the three ability groups were subjected to Analysis of Variance Table 1. Since there was significant difference in the performance of the three groups in pretest, Analysis of covariance was used for their scores in post-test.

Table 1: Summary of one-way Analysis of Variance (ANOVA) of pretest score of students in the high, medium and low ability groups

\begin{tabular}{lrrcc}
\hline Source of variation & $d f$ & \multicolumn{1}{c}{$S S$} & \multicolumn{1}{c}{$M S$} & $F$ \\
\hline Between Groups & 2 & 522.1 & 261.00 & $276.5^{*}$ \\
Within Groups & 117 & 110.5 & .944 & \\
\hline Total & 119 & 632.6 & & \\
\hline * Significant at $\mathrm{P}<0.05$ & & &
\end{tabular}

Table 2: Summary of Analysis of Covariance (ANCOVA) of posttest score of students in the high, medium and low ability groups

\begin{tabular}{lrrrl}
\hline Source of variation & $D f$ & $S S$ & $M S$ & $F$ \\
\hline Between Groups & 2 & 4.90 & 2.45 & $1.34^{*}$ \\
Within Groups & 117 & 211.90 & 1.83 & $(\mathrm{~ns})$ \\
\hline Total & 119 & 216.80 & & \\
\hline
\end{tabular}

* Not significant at $\mathrm{P}>0.05$

The result showed that there was no significant difference in the performance of students in the three ability groups in posttest after exposing them to the teacher-directed problemsolving strategy Table 2. Therefore, the stated hypothesis was not rejected.

\section{DISCUSSION}

It is glaring from the results of the study that there was no significant difference in the performances of students in the three ability levels after receiving the problem-solving strategy. This implies that, all the students in the different ability levels were able to solve problems based on electrolysis and its prerequisite concepts after the treatment. This was in support of Adesoji $(1995,1997)$ who observed that problem-solving strategies were effective in teaching students of different ability levels. Ability to solve problems in science could therefore be enhanced by introducing a good teaching strategy. Thus, it could be said that solving problems is not limited to a particular ability level.

The findings supported O'Connor (1959) who reported that the successful and unsuccessful problem-solvers were not restricted to any ability group. Students could perform well in solving problems if exposed to problem-solving strategy. The claim made by Ajeyalemi and Busari (1986) that emphasis on the acquisition of only facts and principles during instruction will not help 
students in topics like electrolysis is fully supported by the results of this study. It is the opinion of this author that students would be helped if engaged in problem-solving activities. This suggestion is in line with what Onwu and Moneme (1985) wrote concerning solving problems based on electrolysis. According to them, students would solve problems on electrolysis very well if they were exposed to the different stages of solving problems. The model adopted for the study involved the use of the different stages of solving chemistry problems (Cf Ashmore et al., 1979 model), which has been shown to enhance students' performance in problem solving. The findings of the study is also in agreement with the efficacy of problemsolving instructional strategies as claimed by researchers such as Adesoji (1992), Okebukola (1992), Lavioe (1993) and Iroegbu (1998).

\section{CONCLUSION}

One of the important attributes of science is solving problems. Consequently, no science students can do without solving problems. The results of the study has, however, indicated that students could be better problem-solvers if they are of high ability level, but, those with low ability could also perfect their problem-solving skills if they are exposed to problem-solving instructional strategy. Therefore, it could be concluded that the disparity in the high and low ability students in solving problems in science is as a result of poor teaching technique, which is common in Nigerian classrooms. This technique has been found to be expository in which students sit down and listen to the teacher without meaningful participation (CfAjeyalemi and Busari, 1986). Adoption of problem-solving instructional technique by the teachers of science would go a along way in improving students' performance in problem-solving tasks.

\section{REFERENCES}

Adesoji, F.A. 1992. A Comparative Analysis of ProblemSolving and Self-Learning Techniques in Teaching Electrolysis. Ph.D Thesis, Ile-Ife: Obafemi Awolowo University.

Adesoji, F.A. 1995. "Students' ability levels and their competence in a self-directed problem-solving task." Ife Journal of Curriculum Studies and Development, 1(1): 55-61

Adesoji, F.A. 1997 "Average Students and Effectiveness of Problem-Solving Instructional Strategies." Ife Journal of Educational Studies, 4(1): 16-19.

Agbayewa, J.O. 1996. "The Effect of Enhanced Problem-Solving Instructional Strategy on Students' Concept Learning in Secondary School Physics." Research in Curriculum Studies, 1(1): 43-48.

Ajeyalemi, D. and O. Busari. 1986. "Factors Associated with Under-Achievement in 'O' Level Chemistry. An Investigation into Classroom Processes, Examination Performance and Teacher and Pupil Opinions." 27th Science Teachers' Association of Nigeria Annual Conference Proceedings, 250-255.

Ashmore, A.D., M. J. Frazer and R. J. Casey. 1979. "Problem-Solving and Problem-solving Networks in Chemistry." Journal of Chemical Education, 56(6): 377-379.

Bello, O.O. 1985. Problem-Solving Instructional Strategies and Students' Learning Outcome in Secondary Schools." Unpublished Ph.D Thesis, Ibadan: University of Ibadan.

Ehindero, O.J. cited from S. O. Oyekan, 1980. "Cognitive Styles, Sex and Achievement in Biology." Journal of Education and Society,(2): 141-152.

Inventash, H.A. 1968. "Comparison of the Effects of Teacher Directed and Self-Directed ProblemSolving on Attitudes and Understanding in Science." Dissertation Abstracts, 29, 497A, No. 2.

Iroegbu, T.O. 1998. Problem-based learning, Numerical ability and Gender as Determinants of Achievement in Line Graphing Skills and Meaningful Learning in Energy Concepts. Unpublished PhD Thesis, Ibadan: University of Ibadan, Nigeria.

Kempa, R.F. and C. E. Dube. 1974. "Science Interest and Attitude Traits in Students' Subsequent to the Study of Chemistry at the Ordinary Level of the G.C.E." Journal of Research in Science Teaching 11(4): 361-370

Kramers-Pals, N., J. Lambrechts and J. Wolff. 1982. "Recurrent Difficulties in Solving Quantitative Problems." Journal of Chemical Education, 59(6): 509-513.

Lavioe, D.R. 1993. "The development, theory and application of cognitive network model of prediction problem solving in biology." Journal of Research in Science Teaching, 30(7): 767 - 785.

Long, J.C. 1981. "The Effect of a DiagnosticPrescriptive Teaching Strategy on Students' Achievement and Attitude in Biology." Journal of Research in Science Teaching, 18(6): 515-523.

Mettes, G.T.C.N., Pilot A., Roosink, M.J. and Kramer pals, N. 1980. "Teaching and Learning ProblemSolving in Science." Journal of Chemical Education, 57(12): 882-885.

Niaz, N. 1996. "Reasoning strategies of students in solving chemistry problems as a function of developmental level, functional mental capacity and disembedding ability." International Journal of Science Education, 18 (5): 525 - 541.

O'Connor, T.T. 1959. "The Problem-solving Processes of High School Students in Physics." Dissertation Abstracts International, NYU 20/10/4003, 601088. 
Okebukola, P.A.O. 1992. "Can good concept mappers be good problem solvers?" Education Psychology, 12(2): 113 - 129

Onwu, G.O. and Moneme, C.O. 1985. "A Network Analysis of Students' Problem-Solving Difficulties in Electrolysis." Journal of Science Teachers" Association of Nigeria, 25(1): 103-114.

Roberts, J.B. 1965. "A Study of the Problem-Solving Processes of Successful and Non-Successful Problem
Solvers in Ninth Grade Science." Dissertation Abstracts, 25, 7088, No.2.

Salami, I.O. 2000. Effect of Three Instructional Modes of Student Teachers' Performance in Selected Teaching Skills. Unpublished PhD Thesis, Ibadan: University of Ibadan. Nigeria.

Usua, A. cited from Oyekan, S.O. 1974 "Cognitive Styles, Sex and Achievement in Biology." Journal of Education and Society,1: 10-19. 